Supporting information

\title{
Experiments and modeling of boric acid permeation through double-skinned forward osmosis membranes
}

\author{
Lin Luo ${ }^{1,2}$, Zhengzhong Zhou ${ }^{3}$, Tai-Shung Chung ${ }^{1,2,4}$, \\ Martin Weber ${ }^{5}$, Claudia Staudt ${ }^{5}$, Christian Maletzko $^{6}$ \\ ${ }^{1}$ NUS Graduate School for Integrative Science and Engineering, National University of \\ Singapore, Singapore 117456 \\ ${ }^{2}$ Department of Chemical and Biomolecular Engineering, National University of Singapore, \\ Singapore 117585 \\ ${ }^{3}$ School of Chemistry \& Chemical Engineering, Jiangsu University, 301 Xuefu Road, \\ Zhenjiang, Jiangsu Province, P. R. China 212013 \\ ${ }^{4}$ Water Desalination \& Reuse (WDR) Ceter, King Abdullah University of Science and \\ Technology, Thuwal 23955-6900, Saudi Arabia \\ ${ }^{5}$ Advanced Materials \& Systems Research, BASF SE, GM-B001, 67056 Ludwigshafen, \\ Germany \\ ${ }^{6}$ Performance Materials, BASF SE, G-PM/PU-F206, 67056 Ludwigshafen, Germany \\ *Corresponding author
}

Tel: +65-65166645; fax: +65-67791936; Email: chencts@nus.edu.sg

Number of pages: 12

Number of figures: 5

Number of tables: 1 


\section{Chemicals}

N-methyl-2-pyrrolidone (NMP, $>99.5 \%$, Merck) and polyethylene glycol with an average molecule weight of 400 (PEG400, Acros) were used as the solvent and additive in the fabrication of membrane supports, respectively. Trimesoyl chloride (TMC) with 98\% purity from Sigma-Aldrich and m-phenylenediamine (MPD) with $>98 \%$ purity supplied by Tokyo Chemical Industry were utilized as the monomers for the interfacial polymerization. Sodium dodecyl sulphate (SDS, $>97 \%$, Fluka) and hexane $(>99.9 \%$, Fisher Chemicals) were employed as the additive and solvent, respectively, during interfacial polymerization. Sodium chloride $(\mathrm{NaCl})$ purchased from Merck was used as the draw solute in FO. Boric acid (Merck) was utilized to prepare the boron feed solution. To detect the boron concentration in the draw solution, utilized chemicals include Ethylenediaminetetraacetic acid disodium salt (EDTA$\mathrm{Na}_{2}$, dehydrate) purchased from Merck, ammonium acetate ( $\left.\geq 98 \%\right)$, Azomethine-H monosodium salt (hydrate) and L-ascorbic acid from Sigma-Aldrich, glacial acetic acid (100\%) from Merck. The deionized (DI) water was produced by a Milli-Q unit (Millipore) with a resistivity of $18 \mathrm{M} \Omega \mathrm{cm}$.

\section{Membrane formation}

To fabricate the flat sheet membrane support, the casting solution was prepared by adding 15 $\mathrm{wt} \%$ sPPSU polymer and $25 \mathrm{wt} \%$ PEG400 into a NMP solvent. After degassing overnight, the dope solution was cast on a glass plate with a casting knife with $100 \mu \mathrm{m}$ in thickness. The as-fabricated membranes were then immersed into a tap water coagulation bath immediately, and kept for 1 day to ensure complete precipitation. All experiments were conducted at room

temperature. Pure water permeability $(P W P)\left(\mathrm{L} \mathrm{m}^{-2} \mathrm{~h}^{-1} \mathrm{bar}^{-1}\right.$ or LMH bar $\left.{ }^{-1}\right)$ of the fabricated 
membrane substrate was tested at room temperature using dead-end RO cells with a transmembrane pressure of 3 bar.

In both single- and double-skinned FO membranes, TFC layers were fabricated via interfacial polymerization following exactly the same procedures. First, the membrane substrates were immersed in an aqueous $2.0 \mathrm{w} . \%$ MPD solution with $0.1 \mathrm{w} . \%$ SDS additive for $2 \mathrm{~min}$. Then they were taken out from the solution, and excess water droplets on the support surface were removed by tissue papers. After that, the support was fixed in a frame and a solution of 0.05 wt. \% TMC in hexane was poured on the top surface for $2 \mathrm{~min}$, which led to the formation of an ultrathin polyamide film. The resultant composite membrane was dried in air for 5 min. Then as-prepared FO membranes were kept in DI water for further tests. In FO operations, the FO membrane is fixed into a lab-scale cross-flow setup, with a membrane area of $1 \mathrm{~cm} \mathrm{x}$ $2 \mathrm{~cm}$. Normally, one FO operation uses one fresh FO membrane.

\section{Boron detection}

The boron concentrations in the feed or draw solutions were measured by the azomethine-H colorimetric method. The details of measurement have been previously reported ${ }^{1,2}$. Buffer masking solution and azomethine-H solution were prepared freshly. To prepare the buffer masking solution, ammonium acetate $(50 \mathrm{~g})$ and EDTA-Na $(3 \mathrm{~g})$ were dissolved in a bottle containing $80 \mathrm{~mL}$ water, then $25 \mathrm{~mL}$ glacial acetic acid was slowly added into the mixture with stirring. Then the azomethine-H solution was prepared by dissolving $0.45 \mathrm{~g}$ of azomethine-H reagent and $1 \mathrm{~g}$ of L-ascorbic acid in $100 \mathrm{~mL}$ DI water. During tests, $1 \mathrm{~mL}$ of the sample boron solution firstly mixed with $2 \mathrm{~mL}$ of the buffer-masking solution, followed by the addition of $2 \mathrm{~mL}$ of the azomethine-H solution. After $30 \mathrm{~min}$, the absorbance of the mixture is measured at $410 \mathrm{~nm}$ by a UV-vis spectrometer. 


\section{Modeling of single-skinned FO membranes}

For the special case when the active layer2 does not exist (i.e., a single-skinned membrane under the FO operation mode, $B_{2} \rightarrow \infty$ and $\left.1 / B_{2} \rightarrow 0\right)$ and the other parameters $\left(B_{1}\right.$ and $\left.K_{m}\right)$ are identical, eq 14 and 15 could be simplified to:

$$
\begin{gathered}
J_{B, A L-F S}=\frac{B_{1}}{1+\frac{B_{1}}{J_{W}}} C_{F} \\
R_{A L-F S}=1-\frac{B_{1}}{J_{W}+B_{1}}
\end{gathered}
$$

On the other hand, in the case of a single-skinned membrane under the AL-DS mode, we consider the active layer 1 in Figure 1 does not exist $\left(B_{1} \rightarrow \infty, 1 / B_{1} \rightarrow 0\right)$, eq 14 and 15 become:

$$
\begin{aligned}
& J_{B, A L-D S}=\frac{1}{\frac{1}{B_{1}}+\frac{1}{J_{W}}+\frac{1}{B_{2} \exp \left(J_{W} / K_{m}\right)}} C_{F}=\frac{1}{\frac{1}{J_{W}}+\frac{1}{B_{2} \exp \left(J_{W} / K_{m}\right)}} C_{F}=\frac{B_{2} \exp \left(J_{W} / K_{m}\right)}{1+\frac{B_{2} \exp \left(J_{W} / K_{m}\right)}{J_{W}}} C_{F} \\
& R_{A L-D S}=1-\frac{1}{\frac{J_{W}}{B_{1}}+1+\frac{J_{W}}{B_{2} \exp \left(J_{W} / K_{m}\right)}}=1-\frac{1}{1+\frac{J_{W}}{B_{2} \exp \left(J_{W} / K_{m}\right)}}=1-\frac{B_{2}}{B_{2}+\frac{J_{W}}{\exp \left(J_{W} / K_{m}\right)}}
\end{aligned}
$$

In our experiments, the same single-skinned FO membrane was fabricated with a TFC layer formed on top of the support, and tested in both AL-DS and AL-FS modes. The boron permeability coefficient of this selective layer is characterized as $B_{1}$. Therefore, eq S3 and S4 become:

$$
\begin{aligned}
& J_{B, A L-D S}=\frac{B_{1} \exp \left(J_{W} / K_{m}\right)}{1+\frac{B_{1} \exp \left(J_{W} / K_{m}\right)}{J_{W}}} C_{F} \\
& R_{A L-D S}=1-\frac{B_{1}}{B_{1}+\frac{J_{W}}{\exp \left(J_{W} / K_{m}\right)}}
\end{aligned}
$$

The results of single-skinned FO membranes are presented in Table 1, and they have been reported in ${ }^{3}$.

\section{Experimental membrane performance of boron flux and boron rejection}


The measured boron flux and boron rejection based on eq 3 and 4 are illustrated in Figure S3. In the case of single-skinned FO membranes, the AL-FS mode is superior because it has a lower boron flux and a higher rejection than the AL-DS mode. This could be explained by the ICP of boron within the support and the high water flux in the AL-DS mode. As a result, boron passage is enhanced by the increased boron concentration difference across the active layer and the water flux coupled convective flow ${ }^{3,4}$. On the other hand, double-skinned FO membranes present greater boron retention rates with a lower boron flux, thanks to its additional second TFC layer and smaller water flux, even though a concentrative ICP of boron also happens within the membrane support layer. Theoretically, the boron transport in FO processes is mainly determined by its concentration difference across the active layer and the convective flow. Thus, the water flux and the severity of ICP together define the boron passage behaviors. 


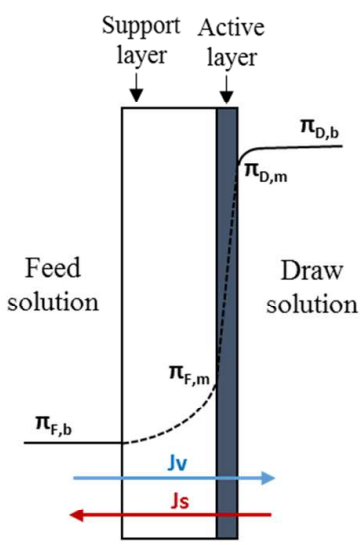

(A) AL-DS mode

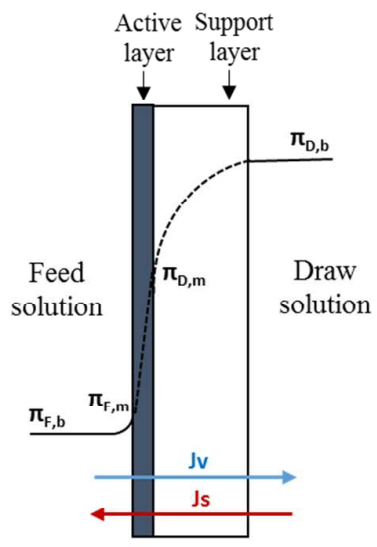

(B) AL-FS mode

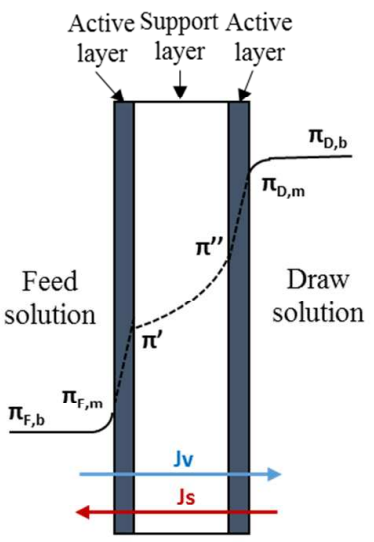

(C) DS mode

Figure S1. Water transport mechanisms of different operational modes in forward osmosis processes 


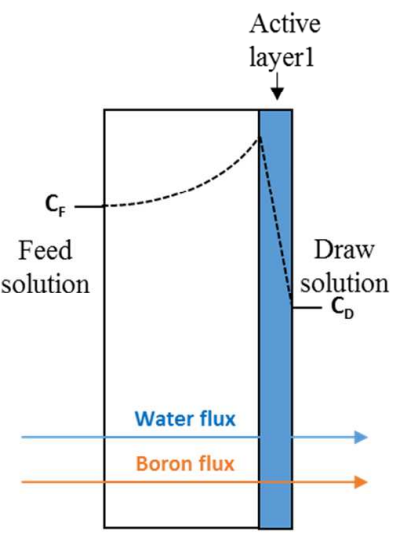

(A) AL-DS mode

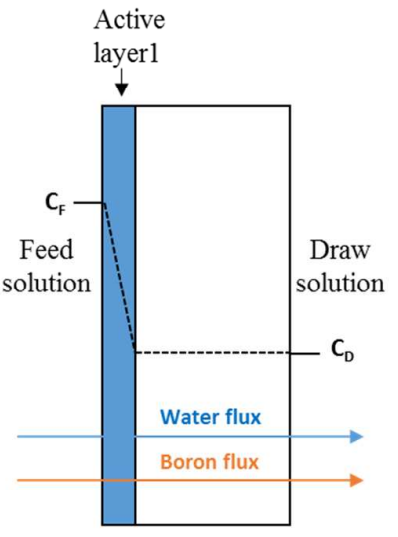

(B) AL-FS mode

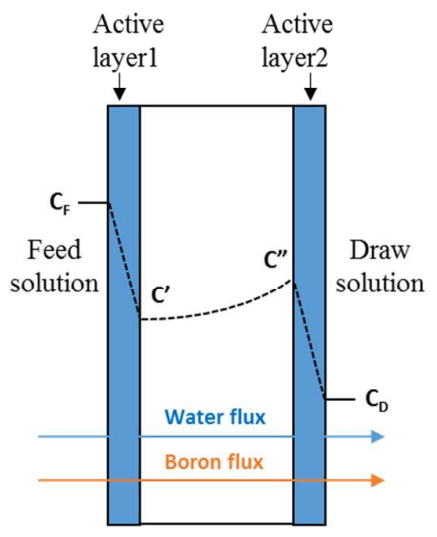

(C) DS mode

Figure S2. Schematic of boron transport within FO membranes: (A) AL-DS mode, (B) AL-FS mode and (C) Double-skinned (DS) mode 

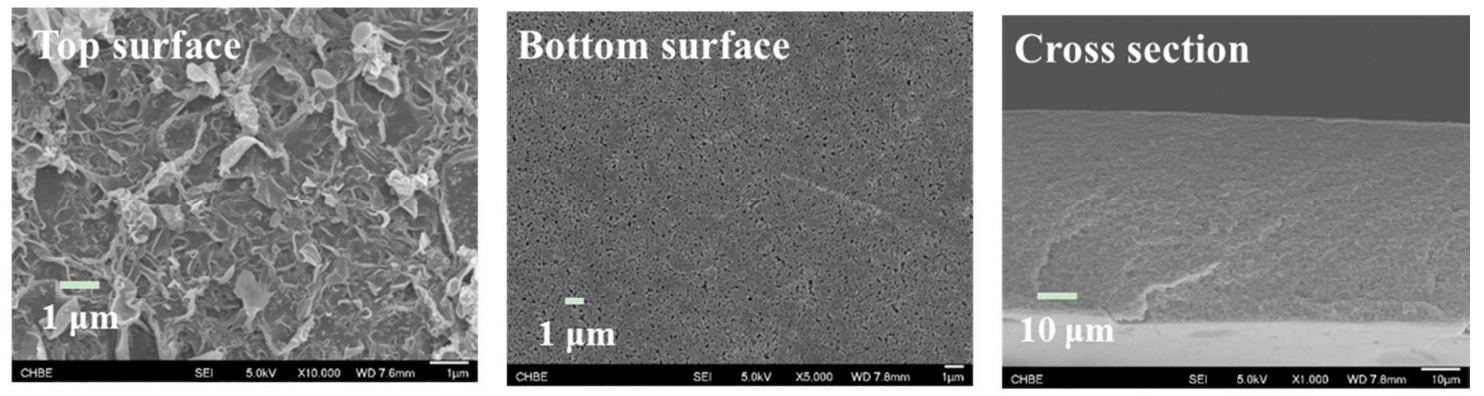

Figure S3. Morphologies of the single-skinned FO membranes 


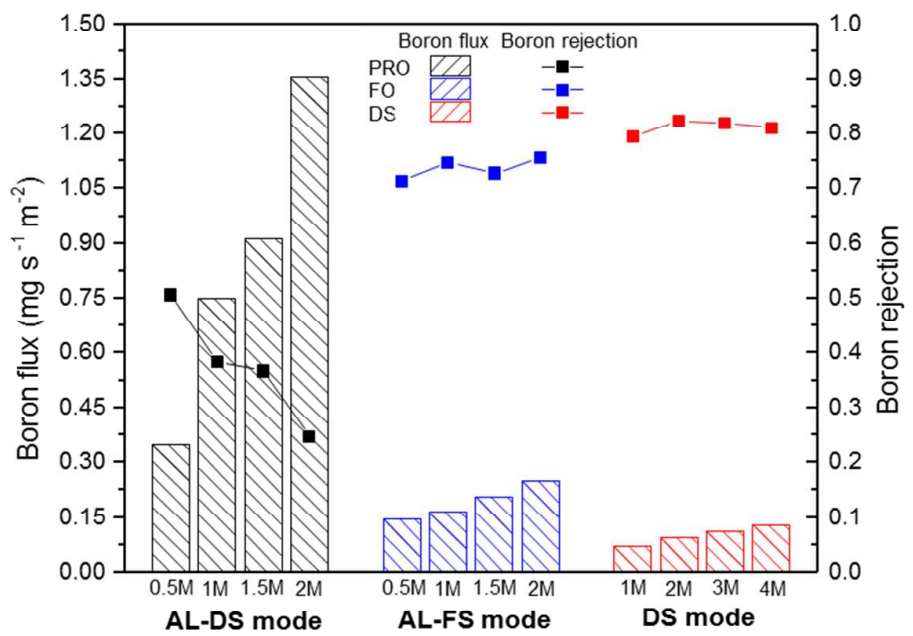

Figure S4. Experimental membrane performance of boron flux and boron rejection in different operation modes (Draw solutions: $0.5 \mathrm{M} \sim 4 \mathrm{M} \mathrm{NaCl}$, feed solution: $100 \mathrm{ppm}$ boron solution ( $\mathrm{pH}$ 6.6)) 

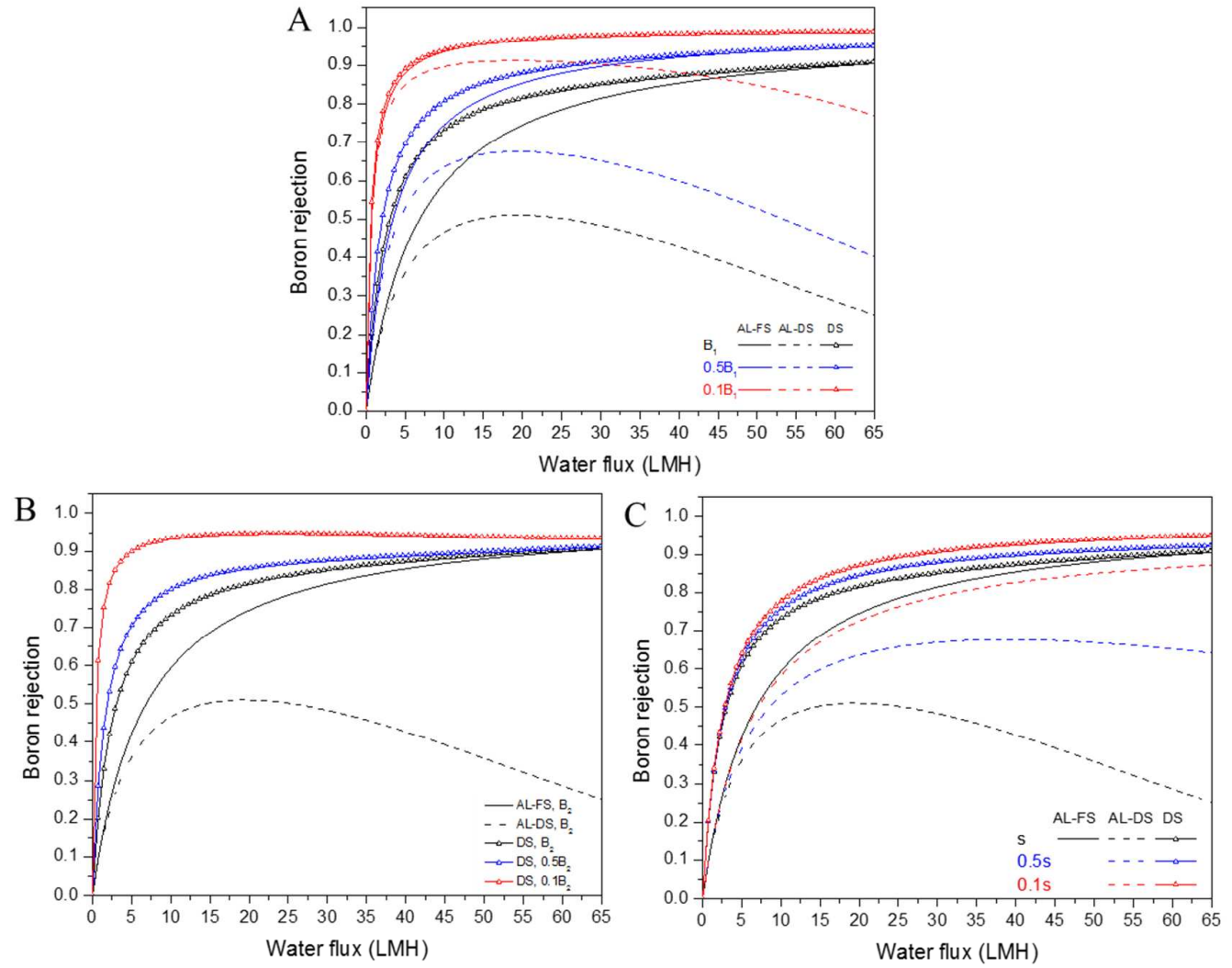

Figure S5. Predictions of boron rejection of three modes under the influence of (A) boron permeability of the active layer1 $B_{l}$, (B) boron permeability of active layer2 $B_{2},(\mathrm{C})$ structure parameter $S$ 
Table S1. Comparison of FO membranes in boron rejection studies

\begin{tabular}{|c|c|c|c|c|}
\hline FO Membranes & Testing conditions & $\begin{array}{c}\text { Boron } \\
\text { rejection }\end{array}$ & $\begin{array}{c}\text { FO } \\
\text { performance }\end{array}$ & Reference \\
\hline $\begin{array}{l}\text { Double-skinned TFC } \\
\text { FO membrane }\end{array}$ & $\begin{array}{l}100 \mathrm{ppm} \text { boron feed solution ( } \mathrm{pH} \\
6.6) ; 4 \mathrm{M} \mathrm{NaCl} \text { draw solution }\end{array}$ & $83.9 \%$ & 21.9 LMH & This work \\
\hline $\begin{array}{l}\text { HTI CTA-HW FO } \\
\text { membrane }\end{array}$ & $\begin{array}{l}5 \mathrm{ppm} \text { boron feed solution ( } \mathrm{pH} 6) \\
5 \mathrm{M} \mathrm{NaCl} \text { draw solution }\end{array}$ & $62 \%$ & $24.8 \mathrm{LMH}$ & 3,5 \\
\hline HTI CA FO membrane & $\begin{array}{l}80 \mathrm{ppm} \text { boron feed solution ( } \mathrm{pH} \mathrm{7)} \\
5 \mathrm{M} \mathrm{NaCl} \text { draw solution }\end{array}$ & $\sim 70 \%$ & $\sim 21.6 \mathrm{LMH}$ & 4 \\
\hline $\begin{array}{l}\text { TFC FO membrane } \\
\text { (from Woongjin } \\
\text { Chemicals) }\end{array}$ & $\begin{array}{c}80 \mathrm{ppm} \text { boron, } 5 \mathrm{ppm} \mathrm{NaCl} \text { feed } \\
\text { solution (pH neutral); } 2 \mathrm{M} \mathrm{KCl} \\
\text { draw solution }\end{array}$ & $\sim 60 \%$ & $\sim 23.4 \mathrm{LMH}$ & 6 \\
\hline
\end{tabular}




\section{Reference}

1. López, F. J.; Giménez, E.; Hernández, F., Analytical study on the determination of boron in environmental water samples. Fresen. J. Anal. Chem. 1993, 346, (10-11), 984-987.

2. Jakšić, L. N., The spectrophotometric determination of boron in tourmalines. J. Serb. Chem. Soc. 2005, 70, (2), 255-260.

3. Jin, X.; Tang, C. Y.; Gu, Y.; She, Q.; Qi, S., Boric acid permeation in forward osmosis membrane processes: modeling, experiments, and implications. Environ. Sci. Technol. 2011, 45, (6), 2323-2330.

4. Kim, C.; Lee, S.; Shon, H. K.; Elimelech, M.; Hong, S., Boron transport in forward osmosis: Measurements, mechanisms, and comparison with reverse osmosis. J. Membr. Sci. 2012, 419-420, (0), 42-48.

5. Jin, X.; She, Q.; Ang, X.; Tang, C. Y., Removal of boron and arsenic by forward osmosis membrane: Influence of membrane orientation and organic fouling. J. Membr. Sci. 2012, 389, (0), 182-187.

6. Fam, W.; Phuntsho, S.; Lee, J. H.; Cho, J.; Shon, H. K., Boron transport through polyamide-based thin film composite forward osmosis membranes. Desalination 2014, 340, (0), 11-17. 